This is an informal report intended primarily for internal or limited external distribution. The opinions and conclusions stated are those of the author and may or may not be those of the laboratory.

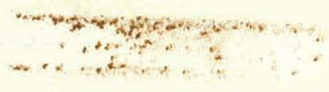

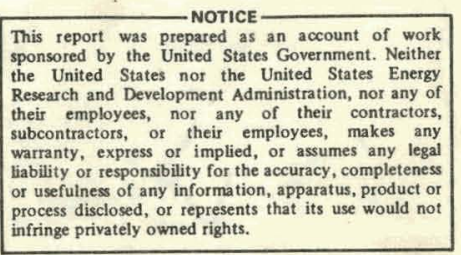

process disclosed, or represents
infringe privately owned rights.

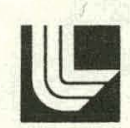

LAWRENCE LIVERMORE LABORATORY

University of California/Livermore, California

\title{
AN ASSESSMENT OF HAZARDS RESULTING FROM ATMOSPHERIC PROPANE EXPLOSIONS AT LLL
}

S. B. Sutton

E. W. McCautey

February 1975 


\section{DISCLAIMER}

This report was prepared as an account of work sponsored by an agency of the United States Government. Neither the United States Government nor any agency Thereof, nor any of their employees, makes any warranty, express or implied, or assumes any legal liability or responsibility for the accuracy, completeness, or usefulness of any information, apparatus, product, or process disclosed, or represents that its use would not infringe privately owned rights. Reference herein to any specific commercial product, process, or service by trade name, trademark, manufacturer, or otherwise does not necessarily constitute or imply its endorsement, recommendation, or favoring by the United States Government or any agency thereof. The views and opinions of authors expressed herein do not necessarily state or reflect those of the United States Government or any agency thereof. 


\section{DISCLAIMER}

Portions of this document may be illegible in electronic image products. Images are produced from the best available original document. 
AN ASSESSMENT: OF HAZARDS RESULTING FROM

ATMOSPHERIC PROPANE EXPLOSIONS AT LLL

$\underline{\text { INTRODUCTION }}$

Due to recent shortages of natural gas, LLL has plans for creating a liquid propane tank farm, consisting of eight 30,000 gallon (maximum volume) storage tanks, to meet its interruptable gas service requirements. We ${ }^{\dagger}$ were asked by Hazards Control ${ }^{1}$ to assess the hazards that would result if a propane explosion were to occur. In an earlier memo ${ }^{2}$, Hazards Control was apprised of foreseen hazards based on preliminary calculations. The present document reports subsequent, more refined, calculations performed for two classes of accident initiation:

1. Catastrophic Failure and Explosion of a Tank

This is likely to be the situation that would occur if the tank were subjected to fire heating, causing catastrophic failure of the tank due to high internal pressures. The fuel then expands violently, mixing with air and subsequently burning. Due to the rapid nature of this phenomenon, frequently called a "Bleeve", t† it is best characterized as an instantaneous energy release.

2. Failure of a supply line resulting in uncontrolled steady spillage of either liquid or vapor. Then, due to prevailing wind conditions, a downwind vapor cloud forms whose location and dimensions are steady with time. It is this vapor cloud which is assumed to ignite and burn. This class of accident is termed a slow leak release.

For each of these accident classifications, two types of calculations were performed:

1. Blast wave analysis to calculate explosion overpressure values.

2. Radiative flux analysis to determine the heat radiation rate from the hot burned gases.

We have assumed that only one of the eight tanks can fail at any one time, and have not considered the effects that one exploding tank may have on the

\footnotetext{
Thermo Fluid Mechanics Group, Nuclear TesL Enyineering Division. t十"Bleeve" is an acronym for boiling liquid expanding vapor explosions.
} 
other tanks. Plant Engineering ${ }^{3}$ proposes that the tanks will be filled to $86.5 \%$ of their maximum volume. Since however, overfills have reportedly occurred, calculations were performed for both $100 \%$ and $86.5 \%$ fill situations. Calculational details are summarized below. For future reference propane properties are summarized in Table I.

\section{OVERPRESSURE CALCULATIONS}

For a number of years, researchers have been attempting to develop accurate techniques for predicting blast wave overpressures from unconfined atmospheric explosions. A number of technical obstacles have continually plágued their efforts. Exact combustion phenomenon are virtually impossible to predict. The combustion process is strongly dependent on atmospheric disturbances, e.g., large scale mixing and turbulence; and air-fuel mixture nonuniformity and mixture cloud shape. In addition, atmospheric characteristics, e.g., large vortexs, turbulence, and humidity influence prediction of blast wave propagation.

Two principle approaches to the problem have evolved. Efforts have been made to numerically solve the elementary wave equations. However, only moderate successes have resulted largely due to the aforementioned combustion and atmosphere variants. Significantly more effort has been employed to develop scaling laws, allowing one to relate predicted explosions to experimental observations. Again, due to the combustion and atmosphere variants, exact predictions are virtually impossible. However, results of this method tend to be more reliable due to the extensive efforts to relate predictions to experimental observations. It is this latter method that we have chosen to use here.

The scaling law method is described by Decker ${ }^{4}$. Since the explosive effects from high explosives, primarily TNT, have been extensively studied and because high explosive phenomenon are generally very predictable the scaling laws attempt to relate gaseous explosions to TNT explosions. It has been observed that TNT closely follows Sack's cube root law

$$
\frac{R_{2}}{R_{1}}=\left(\frac{W_{2}}{W_{1}}\right)^{1 / 3}
$$

where

$$
\begin{aligned}
R_{1}, R_{2}= & \text { ranges from respertive sources where a particular } \\
& \text { overpressure occurs. }
\end{aligned}
$$


$W_{1}, W_{2}=$ source energies

This equation can be rearranged into what is commonly called the scaled range form:

$$
\frac{R_{1}}{w_{1}^{1 / 3}}=\frac{R_{2}}{w_{2}^{1 / 3}}=\lambda \text {. }
$$

This formalism allows one to relate effects of a TNT explosion to catagorized effects of another TNT explosion of a strikingly different energy value. A typical scaled range overpressure curve for TNT is shown in figure 1.

It has also been observed that gas and chemical explosion behavior frequently follow these same relations. Thus in theory it seems possible to relate gas and chemical explosion effects to TNT explosive effects which have been much more closely studied and are much more predictable. This is precisely what is done in the scaling law method of studying gas and chemical explosions. This use of curves based on TNT data to predict explosion overpressures resulting from chemical or gas explosions entails several simplifications. There are major differences between TNT burns and gas burns. Typically both burn pressures and burn velocities are much larger in TNT, which burns in a detonation fashion, than gas fuel-air mixtures which can either detonate or deflagrate. Also, the percent of theoretical energy released in a TNT explosion is typically larger than in gas or chemical explosions. To account for these differences, Decker ${ }^{4}$ calculates the gas or chemical energy in terms of equivalent pounds of TNT using the equation

$$
\text { TNT Eq. }=\frac{\varepsilon \cdot V_{F} \cdot \Delta H_{C}}{2.11 \times 10^{6}}
$$

where

$$
\begin{aligned}
V_{F}= & \text { total volume of fuel within the combustible limits } \\
\Delta H_{C}= & \text { combustion energy in units of joules per unit volume } \\
& \text { at S.T.P. } \\
\varepsilon \quad & \text { an emperically determined multiplication factor to account } \\
& \text { for incomplete cumiluisliun ds well as differences between } \\
& \text { TNT blast and gas explosions. }
\end{aligned}
$$


It is important to note that the effects of these differences can be minimized to well within the uncertainty bands associated with combustion and atmospheric variants.

The major difficulty still remaining is to determine appropriate values of the empirical factor $\varepsilon$. Brasie and Simpson ${ }^{5}$ as we11 as Decker ${ }^{4}$ discuss appropriate values of this multiplication factor for various explosion situations. Decker concludes that for instantaneous releases, involving hydrocarbon fuels, an appropriate value is .10. This value assumes a deflagration burn type as well as accounts for incomplete combustion. For slow release situations he concludes that an $\varepsilon$ of 1.0 is appropriate. This larger value is justified from observed phenomenon. For free atmosphere clouds, deflegration waves are typically the burn type. However, detonation waves, which result in significantly higher pressures, have reportedly occurred in a number of slow release accidents. Also, combustion is observed to be very near complete. Thus using an $\varepsilon$ of 1.0 represents a worst case as well as conservative prediction for the slow release situation. Brasie and Simpson suggest lower values (.03-.05) for chemical explosions (non-hydrocarbon deflagration burns). However for hydrogen, a fuel generally considered more explosive than hydrocarbon fuels, they suggest. 3 . We will employ the suggestions of Decker since they will generally result in the most conservative prediction. In this light, it is important to note that the overpressure variation with yield is not linear. From equation 1 we see that the location of a particular pressure varies as the cube-root of the yield. Thus variations in $\varepsilon$ of a factor of 5 will result in only moderate variations in the overpressure.

Further validity is obtained if one relates predicted overpressure to observed damage. Brasie and Simpson ${ }^{5}$ compiled damage data, i.e., damage vs. range, for various source energies. The source energy was calculated using equation 2, after estimating the volume of fuel present in the explosion. Appropriate values of $\varepsilon$, which are thoroughly discussed in their paper and are dependent on the fuel type, were used to account for departures from TNT behavior. Then using Figure 1, they estimated the blast pressure. By comparing damage class to predicted overpressure approprlate damage criteria for use with gas and cherrical sources was developed. This data, further summarized by Decker, is repeated as our Table II. 
To calculate overpressures in the case of a catastrophic failure, i.e., case of instantaneous energy release (Class 1), we assume that the explosion phenomenon occur too rapidly to be affected by atmospheric dispersion and disturbances. We use equation 2 and Figure 1 to determine overpressures. In this situation, $V_{F}$ is the volume the fuel would occupy at standard temperature and pressure. Note that in the case of a fuel originally in a liquid state, we must determine its vapor equivalent volume at standard conditions. As mentioned previously, in equation 2 we use an $\varepsilon$ of .10 to account for incomplete combustion as well as differences between TNT and gas explosion behavior.

For the case of a slow leak (Class 2), we must first determine the dispersed cloud location and volume. Consider the coordinate system in Figure 2, where the $X$-direction is the wind flow direction, the $Y$-direction is perpendicular to the wind flow direction and parallel to the ground, and the Z-coordinate represents the vertical direction. The contaminant source is located at the coordinate system origin at ground level. The steady release of the contaminant will create a variable concentration plume downwind of the contaminant source location given by

$$
X_{C L}=\frac{2.223 \times 10^{-7} Q}{\pi \sigma_{y} \sigma_{z} \bar{u}}
$$

where

$$
\begin{aligned}
X_{C L}= & \begin{array}{l}
\text { centerline concentration downwind in cubic metres } \\
\text { of contaminant per cubic metre of mixture (volume fraction). }
\end{array} \\
Q= & \text { contaminant release rate in cubic metres per } \\
& \text { second (at S.T.P.). } \\
\bar{u} \quad= & \text { mean wind speed in metres per second. } \\
\sigma_{y}= & \text { horizontal diffusion coefficient in metres, as a } \\
& \text { function of the } X \text { distance from the source. } \\
\sigma_{z}= & \text { vertical diffusion coefficient in metres, as a } \\
& \text { function of the } X \text { distance from the source. }
\end{aligned}
$$

Values of $\sigma_{y}^{\prime}$ and $\sigma_{z}$ vary with wind speed, degree of atmospheric turbulence, and distance from the source. Table III ${ }^{4}$ is a summary of $\sigma_{y}$ and $\sigma_{7}$ values for variuus atmospheric conditions. Further, the $Y$ and $Z$ coordinate values of the upper explosive limit concentration (UEL) and the lower explosive limit concen- 
tration (LEL) are given by

$$
\begin{aligned}
& Y_{U E L}=\left[2 \ln \left(\frac{x_{C L}}{x_{U E L}}\right)\right]^{1 / 2} \cdot \sigma_{y} \\
& Z_{U E L}=\left[2 \ln \left(\frac{x_{C L}}{x_{U E L}}\right)\right]^{7 / 2} \cdot \sigma_{z} \\
& Y_{L E L}=\left[2 \ln \left(\frac{x_{C L}}{x_{L E L}}\right)^{1 / 2} \cdot \sigma_{y}\right. \\
& Z_{L E L}=\left[2 \ln \left(\frac{x_{C L}}{x_{L E L}}\right)\right]^{1 / 2} \cdot \sigma_{z}
\end{aligned}
$$

where

$$
\begin{aligned}
& X_{U E L}=\text { upper explosive limit volume fraction. } \\
& X_{L E L}=\text { lower explosive limit volume fraction. }
\end{aligned}
$$

Note that $Y_{U E L}, Z_{U E L}, Y_{L E L}, Z_{L E L}$ are all implied functions of the $X$ distance downwind. Thus one can then generate, as shown in Figure 3 , a set of concentration contours which define the downwind contaminant plume.

To determine the blast source strength, it is necessary to know the volume of gas located in the combustible range, i.e., between the LEL and UEL contours. One will note that the contours approximately represent elliptical curves. Thus by rotation about the principle (major) axis, a prolate spheroid is generated. Because we are only dealing with a half space, the approximate gas volume within a contour is then given by

$$
V=\left(\frac{1}{2} \cdot \frac{2 \pi}{3} a b^{2}\right)
$$

where

$$
\begin{aligned}
& a=\text { Ellipse semi-major axis length. } \\
& b=\text { Ellipse semi-minor axis length. }
\end{aligned}
$$

The volume within the combustible range is the volume of gas between the two proplate spheroid surfaces, or, 


$$
V=V_{L E L}-V_{U E L} \text {. }
$$

Since the $Y$ and $Z$ curves are in general different, we must average the combustible volumes given by rotation of the curves. Thus,

$$
V_{T}=\frac{1}{2}\left\{\left(V_{L E L}-v_{U E L}\right)_{Y_{\text {curves }}}:\left(V_{L E L}-V_{U E L}\right) z_{\text {curves }}\right\}
$$

Now, $V_{F}$ for use in equation 2 is given by

$$
v_{F}=v_{T} x_{F}
$$

where

$$
\begin{aligned}
X_{F}= & \text { average volume fraction of fuel in } \\
& \text { air-fuel mixture. }
\end{aligned}
$$

Also, an $\varepsilon$ of 1.0 is assumed since free atmosphere clouds have reportedly detonated. Thus, equation 2 and Figure 1 can be used to determine approximate overpressures.

\section{HEAT FLUX CALCULATIONS}

In determining radiated heat flux values, it is necessary that we know the volume of burned gases, the gas temperature, and the composition of the burned gas. In all cases, we have assumed that the gas volume after combustion is approximately the same as before ignition. During a gas cloud burn, there will undoubtedly be some expansion of the burned gases before all the gas has undergone combustion. However, we have no way to assess this expansion so we are forced to assume constant volume. We will now discuss the methods used to determine the radiating gas volume.

In a slow leak situation (class 2 ), for the blast wave calculations, the volume of gas mixture within the combustible limits was calculated using equation 6. Since we assume complete combustion, this is identically the volume of burned radiating gas and will be used in the heat flux calculations.

In the case of an instantaneous release, due to incomplete combustion, the burned gas volume will be less than the total air-fuel mixture volume. The total mixture volume is given by 
where

$$
v_{M}=v_{F} / x_{F}
$$

$$
\begin{aligned}
& V_{F}=\text { volume of volume of volatilized fuel } \\
& X_{F}=\text { average volume fraction of fuel in the mixture }
\end{aligned}
$$

We can now take the volume of fuel-air mixture that actually burned to be

$$
\begin{aligned}
V & =\gamma V_{m} \\
& =\gamma V_{F} / x_{F}
\end{aligned}
$$

No guidance exists for selection of an appropriate value of $\gamma$. Since the incomplete combustion phenomenon is largely reflected in the value of $\varepsilon$ in equation 2 , we elect to approximate $\gamma$ as .10 , the same as the value of $\varepsilon$.

In all cases we have taken the burned gas temperature to be the observed flame temperature in air. For propane the temperature is $2198^{\circ} \mathrm{K}$. This should be a good approximation to the radiating temperature at early times when the heat flux is greatest.

The computer code $\operatorname{CCC}^{6}$ was used to determine the equilibrium composition at the flame temperature. The code accounts for generalized species dissociation and recombination. In general, by accounting for dissociation and recombination we are allowing a decrease in the concentration of triatomic molecules and an increase in the concentration of diatomic molecules such as $\mathrm{NO}, \mathrm{OH}, \mathrm{CO}, \mathrm{O}_{2}$. It should be noted that for heat radiating purposes, diatomic molecules, e.g., $\mathrm{N}_{2}$, NO, CO, may be regarded as transparent and non-radiating. It is only substances such as $\mathrm{CO}_{2}$ and $\mathrm{H}_{2} \mathrm{O}$ which have appreciable emissivities and absorptivities. Thus, by including dissociation and recombination, our results will be much more reasonable than if these effects were excluded. Since radiative heat transfer rates vary as $\mathrm{T}^{4^{*}}$, we may neglect radiation from the atmosphere impinging on the volume of burned gases because $\left(T_{g}^{4}-T_{\text {air }}^{4}\right) \approx T_{g}^{4}$. If we consider the gas to be enclosed by a transparent, non-reflecting surface, then the radiation from the burned gas impinging on this surface is given by ${ }^{7}$

$$
Q / A_{S}=\varepsilon \sigma T_{g}^{4}
$$

\footnotetext{
ॠ The symbol T represents temperature.
} 
where

$$
\begin{aligned}
& \varepsilon=\text { gas emissivity } \\
& \sigma=\text { Stephan-Boltzman constant } \\
& T_{g}=\text { the burned gas temperature } \\
& A_{S}=\text { surface area of transparent membrane surrounding the gas. }
\end{aligned}
$$

For most hydrocarbon burns, where the only significant triatomic molecules in the burned gases are $\mathrm{CO}_{2}$ and $\mathrm{H}_{2} \mathrm{O}$, the emissivity of the burned gas is given by

$$
\varepsilon_{\mathrm{g}}=\varepsilon_{\mathrm{CO}_{2}}+\varepsilon_{\mathrm{H}_{2} \mathrm{O}}-\Delta \varepsilon
$$

where

$$
\begin{aligned}
{ }_{\mathrm{CO}_{2}}= & \text { Emissivity of the } \mathrm{CO}_{2} \text { gas. } \\
\varepsilon_{\mathrm{H}_{2} \mathrm{O}}= & \text { Emissivity of the water vapor. } \\
\Delta \varepsilon \quad= & \text { A correction factor to account for } \\
& \begin{array}{l}
\text { overlapping absorption and emission } \\
\text { bands of the two gases. }
\end{array}
\end{aligned}
$$

Referring to Siegel and Howell ${ }^{7}$,

$$
\begin{aligned}
& { }_{\mathrm{CO}_{2}}={ }_{\mathrm{CO}_{2}} \cdot\left({ }^{\varepsilon_{\mathrm{CO}_{2}}}\right)_{\mathrm{atm}} \\
& \varepsilon_{\mathrm{H}_{2} \mathrm{O}}=\mathrm{C}_{\mathrm{H}_{2} \mathrm{O}} \cdot\left(\varepsilon_{\mathrm{H}_{2} \mathrm{O}}\right)_{\mathrm{atm}}
\end{aligned}
$$

where

$$
\begin{aligned}
& \left(\varepsilon_{\mathrm{CO}_{2}}\right)_{\mathrm{atm}},\left(\varepsilon_{\mathrm{H}_{2} \mathrm{O}}\right)_{\mathrm{atm}}=\begin{array}{l}
\text { Emissivities of the } \\
\text { gases when the total gas }
\end{array} \\
& \text { pressure is one atmosphere } \\
& \begin{aligned}
\mathrm{C}_{\mathrm{CO}_{2}}, \mathrm{C}_{\mathrm{H}_{2} \mathrm{O}}= & \text { Correction factors to account for a gas } \\
& \text { mixture whose total pressure is not one }
\end{aligned} \\
& \text { a tmosphere }
\end{aligned}
$$


Referring to Figures 4,5 and 6 , one will note that these parameters are functions of the gas partial pressure and the mean beam length ${ }^{\dagger+}, \mathrm{L}_{e}$. The gas partial pressures are given by

$$
\begin{aligned}
& P_{\mathrm{H}_{2} \mathrm{O}}=X_{\mathrm{H}_{2} 0^{P}} \\
& P_{\mathrm{CO}_{2}}=X_{\mathrm{CO}_{2}}{ }^{P}
\end{aligned}
$$

where

$$
\begin{aligned}
& X_{\mathrm{H}_{2} \mathrm{O}}, X_{\mathrm{CO}_{2}}=\text { volume fractions } \\
& P=\text { gas mixture total pressure }
\end{aligned}
$$

If we assume that the gas volume is approximately spherical in shape;

where

$$
L_{e}=.65 D \quad(\text { from Reference } 7)
$$

$$
D=\text { the gas sphere diameter. }
$$

Using these relations and charts, one can determine the gas mixture emissivity and from equation 8 the heat flux impinging on the transparent spherical boundary. Since the atmosphere is composed primarily of diatomic gases (>98\%), which are non-absorbing and non-radiating, we will regard the surrounding air as transparent. Thus the radiative flux may be scaled as

$$
Q_{2}=Q_{1}
$$

or

$$
\frac{Q_{2}}{A_{2}}=\frac{Q_{1}}{A_{1}} \frac{A_{1}}{A_{2}}=\frac{Q_{1}}{A_{1}} \times\left(R_{1} / R_{2}\right)^{2}
$$

where

$$
Q_{i}=\text { total energy crossing surfaces at } R_{i}
$$

\footnotetext{
t† The mean beam length is the average distance a radiated photom must travel to leave the radiating gas.
} 
and

$$
\begin{aligned}
& Q_{1} / A_{1}=\text { flux value obtained from equation } 8 \\
& A_{2}, A_{1}=\text { spherical surface areas } \\
& R_{1}, R_{2}=\text { radii of spherical surfaces. }
\end{aligned}
$$

The above relations can be used to obtain plots of heat flux vs. range from source center.

\section{CALCULATIONAL DETAILS}

In the previous section we developed the necessary equations to perform overpressure and heat flux calculations. We will now give details of calculations performed for the LLL propane tank farm.

\section{Overpressure Calculations}

First we will consider the instantaneous release case (class 1 ) representing an upper limit situation. Atmospheric dispersion need not be considered. Calculations were performed for tanks filled to both $100 \%$ and $86.5 \%$ of the maximum volume. The equivalent energy calculations, obtained from equation 2 are summarized in Table IV. The resulting overpressure curves, extracted from Figure 1 and making the appropriate unit changes are given in Figure 7.

Slow leak calculations (class 2), where we must consider atmospheric dispersion and vapor cloud formation, were performed for both gaseous and liquid discharges. We will now describe the methods used to determine propane flow rates. First consider the liquid discharge case. Figure 8 is a schematic representation of the liquid discharge situation. We will apply Bernoulli's equation to determine the liquid discharge rate under the assumptions that

1. The opening at 2 is small such that the variation of $h$ with time is negligible or that the pressure at 1 is Iluch larger than the pressure head due to the fluid column of height $h$.

2. The fluid velocity at surface 1 is negligible compared to the velocity at 2 ; i.e., $v_{1}^{2} \ll v_{2}^{2}$.

With these restrictions, the exit velocity is given by 


$$
v_{2}=\sqrt{2 g h+2 v\left(P_{1}-P_{2}\right)} \text {. }
$$

Discharge is to the atmosphere, $P_{2}=1 \mathrm{~atm}=100 \mathrm{KPa}$. Also, $P_{1}$ is the vapor pressure of propane at $70^{\circ} \mathrm{F}$, which from Table $I$ is $956.6 \mathrm{KPa}$, and $\mathrm{h}$ is the tank height which is $3.048 \mathrm{~m}$. From Table I, the specific volume ( $v$ ) of liquid propane is $1.967 \mathrm{~m}^{3} / \mathrm{Mg}$.

One will note that the pressure at 1 is much larger than the pressure head due to the fluid column. Also it seems reasonable that for a 3 inch opening at 2 , the surface velocity $\left(V_{1}\right)$ will be negligible compared to $V_{2}$. Thus both assumption 1 and assumption 2 are satisfied. Therefore $V_{2}=57.50 \mathrm{~m} / \mathrm{sec}$.

For a 3 inch pipe opening $\left(A=4.56 \times 10^{-3} \mathrm{~m}^{2}\right)$ the mass flow rate is

$$
\begin{aligned}
\dot{\mathrm{m}} & =\rho V A \\
& =1.335 \times 10^{5} \mathrm{gm} / \mathrm{sec} \text { ( } 1 \text { iquid release) }
\end{aligned}
$$

Let us now consider a vapor release situation, the maximum flow rate occurs when the gas exits at choked conditions; i.e., sonic velocity (mach number, $M=1$ ). Using one-dimensional isentropic flow, the flow conditions at the throat are given by

$$
\begin{aligned}
M=1 ; \mathrm{P} / \mathrm{P}_{0} & =.525 \\
\rho / \rho_{0} & =.632 \\
\mathrm{~T} / \mathrm{T}_{0} & =.833
\end{aligned}
$$

where the o subscript denotes stagnation or reservoir conditions. Assuming an ideal gas we may write

$$
V=M C=M \sqrt{\gamma R T}
$$

where

$$
\begin{aligned}
& V=\text { fluid velocity } \\
& C=\text { fluid sound speed } \\
& M=\text { fluid mach number } \\
& \gamma=\text { ratio of specific heats }\left(C_{P} / C_{V}\right) \\
& R=\text { the fluid gas constant } \\
& T=\text { the fluid temperature }
\end{aligned}
$$

From Table I; $\gamma=1.12, \quad R=.189 \frac{\text { Joules }}{\mathrm{gm}{ }^{0} \mathrm{~K}}$. Thus, $V=224 . \mathrm{m} / \mathrm{sec}$. 
As a result, the mass flow rate is $\dot{m}=\rho V A=1.953 \times 10^{4} \mathrm{gm} / \mathrm{sec}$. (Vapor release.)

We have now determined appropriate mass flow rates. In order to calculate the dispersed cloud shape and location we need to know prevailing atmospheric conditions. If one looks at wind currents over the LLL site, the most common wind velocity is $12 \mathrm{miles} /$ hour (or $5.35 \mathrm{~m} / \mathrm{sec}$ ) which from Table II corresponds to a $B_{1}$ stability classification. The calculation could be further extended to determine the worst case situations, i.e., worst velocity-direction combination, and the probabilities associated with such an occurrence. Employing equations 3 and 4 , for Class 2, we get the concentration profiles shown in Figure 9 (liquid release) and Figure 10 (vapor release). The equivalent energy calculations are summarized in Table $V$, and the resulting overpressure $v s$. range curves given in Figure 11.

To estimate damage resulting from an atmospheric explosion we use the data of Brasie and Simpson (Table II). One can infer potential explosion damage to existing LLL facilities by reference to Figure 12, an overlay of predicted blast shock strength on an LLL site map. In the worst possible situation (class 1) structural damage ( 1 to 2 psi overpressure) could conceivably occur as far as 550 metres from the explosion center. Irregardless of the explosion type (class 1 or class 2 ) it is apparent that building 612 could be subjected to pressures sufficient to cause major structural damage. (> 3 psi overpressure). Also, it is clear that glass breakage could conceivably occur as far as 1000 metres from the explosion source.

\section{RADIATIVE FLUX CALCULATIONS}

Results of the CCC calculation, for a gas mixture of $6.1 \%$ propane $\left(\mathrm{C}_{3} \mathrm{H}_{8}\right)$ and 93.9\% air, are given in Table VI. The remaining heat flux calculations are summarized in Table VII. The resulting heat flux vs. range curves are given in Figure 13.

\footnotetext{
Tonclusions reached in consultation with R. Murray ${ }^{8}$, Structural Mechanics Group, Nuclear Test Engineering Division.
} 
We have assessed structure heating damage, due to the radiative heat flux, using the analyses techniques of Simms $^{9}$ and Martin ${ }^{10}$. For wood, Martin has found that the necessary duration time of an impinging constant heat flux to start ignition is given by

$$
H \sqrt{t}=3.35 \times 10^{5}
$$

where

$$
\begin{aligned}
& H=\text { heat flux }\left(\frac{\text { Joules }}{\mathrm{m}^{2} \mathrm{sec}}\right) \\
& t=\text { necessary duration time (seconds) }
\end{aligned}
$$

For the calculated flux values, as given in Table VII and Figure 13, the necessary duration time at very short ranges ( $~ 50$ meter) is greater than 10 seconds for either class of burn, while, at 100 meters this time increases to over four minutes. Since the heat flux eminating from the gas ball is expected to last only on the order of a few seconds $(<5)$, we expect no heating damage (excluding singeing) to surrounding structures. Experimental data on transient fluxes is unavailable. There is however, significant data for steady fires. Fu ${ }^{11}$ has measured the heat fluxes eminating from aviation fuel pool fires. Parker ${ }^{12}$ has experimentally and theoretically studied thermal radiation fluxes from large gas fuel fires. In both cases, the measurements are for steady (steady fuel flow), long duration fires. Accounting for fire size differences, our early time calculated values compare favorably with the flux measurements in both papers.

\section{SUMMARY}

We have presented a viable technique for determining blast wave overpressure and radiatitive heat flux values for hypothetical explosions and failures of propane tanks. Calculated overpressure and heat flux values have been determined for instantaneous energy releases and slow leak releases for a typical 30,000 liquid gallon propane tank at LLL. Based on these calculations, the following prel iminary conclusions regarding hazards may be drawn: ${ }^{\dagger}$

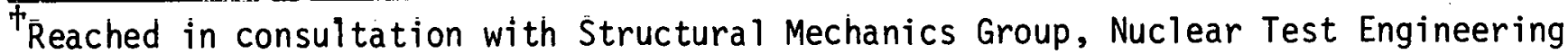
Division.
} 
1. A great potential exists for glass breakage throughout the LLL site in the event of a single tank propane explosion of any type.

2. Minor structural damage in the worst possible explosion situation (class 1), could conceivably occur as far as 550 meters from the explosion center provided the blast wave contacted no major obstacles, i.e., buildings, in transit.

3. Due to the short duration of radiated heat fluxes, no fire potential exists for combustible materials, primarily wood, located greater than 50 metres from the explosion center.

4. Finally, we must stress that these calculations appear conservative, i.e., worst conceivable situation.

We have not mentioned, nor have we extensively studied, possible solutions to these hazards. We do however feel that the following measures deserve further consideration and study:

1. Revetment for trenching of the tanks - The revetments could be used to isolate the tank complex as a whole, as. well as isolate tanks from one another. The revetments will offer blast shielding protection only for catastrophic accident (ground level blast) situations (class 1). The explosion center for slow leak cases (class 2) will in general be too far above ground level for revetmenting to be effective.

2. Detection devices to determine the advent of a slow leak (class 2) Because we are dealing with a wind blown cloud, there appears to be little else that can be done to protect personnel other than to provide ample warning if evacuation is necessary. 


\begin{tabular}{|c|c|}
\hline & \\
\hline Molecular weight & 44. \\
\hline $\begin{array}{l}\text { Density of liquid } \\
\text { at S.T.P. }\end{array}$ & $.5078 \frac{\mathrm{Mg}}{\mathrm{m}^{3}}$ \\
\hline $\begin{array}{l}\text { Specific volume of gas } \\
\text { at S.T.P. }\end{array}$ & $.534 \frac{\mathrm{m}^{3}}{\mathrm{kgm}}$ \\
\hline Vapor pressure at $70^{\circ} \mathrm{F}$ & $954.9 \mathrm{KPa}$. \\
\hline $\begin{array}{l}\text { Observed flame } \\
\text { temperature in air }\end{array}$ & $2198^{\circ} \mathrm{K}$ \\
\hline $\begin{array}{l}\text { Combustibility } 1 \text { imits } \\
\text { in air-volume } \% \text { fuel }\end{array}$ & \\
\hline Upper & $10.1 \%$ \\
\hline Lower & $2.1 \%$ \\
\hline $\begin{array}{l}\text { Heating value of } \\
\text { gas at S.T.P. }\end{array}$ & $9.6 \times 10^{7} \cdot \frac{\mathrm{J}}{\mathrm{m}^{3}}$ \\
\hline Gas constant & $.189 \frac{\text { Joules }}{\mathrm{gm}^{\circ} \mathrm{K}}$ \\
\hline $\begin{array}{r}\text { Specific heat ratio } \\
(\gamma)\end{array}$ & 1.12 \\
\hline
\end{tabular}


TABLE II

FAILURE LEVELS FOR

TYPICAL STRUCTURE CONFIGURATIONS

\begin{tabular}{|l|l|l|}
\hline \multicolumn{1}{|c|}{ Structural Element } & \multicolumn{1}{|c|}{ Usual Failure } & $\begin{array}{c}\text { Peak Blast } \\
\text { Overpressure }\end{array}$ \\
\hline Glass Windows & Shattering & $0.5-1.0 \mathrm{psi}$ \\
Corrug. Asbestos Siding & Shattering & $1.0-2.0 \mathrm{psi}$ \\
Corrug. Steel Paneling & Connection Failure & $1.0-2.0 \mathrm{psi}$ \\
Wood Siding & Connection Failure & $1.0-2.0 \mathrm{psi}$ \\
$\begin{array}{c}\text { Concrete or Cinder Block } \\
\text { Wall (not reinforced) }\end{array}$ & Wall Shattering & $2.0-3.0 \mathrm{psi}$ \\
$\begin{array}{l}\text { Telephone Pole } \\
\text { Brick Wall Panei 8-12 in. } \\
\text { thick (not reinforced) }\end{array}$ & $\begin{array}{l}\text { Shearing \& Flexure } \\
\text { Failures }\end{array}$ & $5.0 \mathrm{psig}$ \\
\hline
\end{tabular}


TABLE III

SUMMARY OF ATMOSPHERIC CONDITIONS 4

\begin{tabular}{|c|c|c|c|c|c|}
\hline Classification & $\begin{array}{l}\text { Fluctuation of } \\
\text { Horizontal } \\
\text { Wind } \\
\text { Direction }\end{array}$ & $\begin{array}{l}\text { Frequency of } \\
\text { Occurrence } \\
\text { Per cent of } \\
\text { Time }\end{array}$ & $\begin{array}{l}\text { Wind Speed } \\
\mathrm{m} / \mathrm{sec}\end{array}$ & $\begin{array}{c}\text { Plume Dispersion } \\
\sigma_{y}\end{array}$ & $\begin{array}{c}\text { Coefficients, } m \\
\sigma_{z}\end{array}$ \\
\hline $\begin{array}{c}\text { A - Extremely } \\
\text { unstable }\end{array}$ & $>90^{\circ}$ & 1 & 1.798 & - & - \\
\hline $\mathrm{B}_{2}$ - Unstable & $45^{\circ}-90^{\circ}$ & 3 & 3.78 & $.3595[x]^{0.91}$ & $.3685[x]^{0.91}$ \\
\hline $\mathrm{B}_{1}-$ Unstable & $15^{\circ}-45^{\circ}$ & 42 & 6.95 & $.3048[x]^{0.86}$ & $.2806[x]^{0.86}$ \\
\hline C - Neutral & $>15^{\circ}$ & 14 & 10.67 & $.2476[x]^{0.78}$ & $.1693 \cdot[x]^{0.78}$ \\
\hline$D$ - Stable & $<15^{\circ}$ & 40 & - & $.2185[x]^{0.71}$ & $.0437[x]^{0.71}$ \\
\hline
\end{tabular}


TABLE IV

SUMMARY OF EQUIVALENT ENERGY

CALCULATIONS FOR INSTANTANEOUS ENERGY RELEASE (CLASS 1)

\begin{tabular}{|c|c|c|}
\hline Property & $100 \% \mathrm{Fill}$ & $86.5 \% \mathrm{Fill}$ \\
\hline Liquid Volume (Gallons) & 30,000 & 25,590 \\
Gas Volume (M $\left.{ }^{3}\right)$ & 30,509 & 26,390 \\
Heat of Combustion & $9.6466 \times 10^{7}$ & $9.6466 \times 10^{7}$ \\
$\left(\mathrm{~J} / \mathrm{M}^{3}\right)$ & .10 & .10 \\
$\varepsilon$ & 139,509 & 120,675 \\
T.N.T. EQ (LB) & & \\
\hline
\end{tabular}

TABLE V

SUMMARY OF EQUIVALENT ENERGY

CALCULATIONS FOR SLOW LEAK CASES

\begin{tabular}{|c|c|c|}
\hline Property & $\begin{array}{c}\text { Liquid } \\
\text { Release }\end{array}$ & $\begin{array}{c}\text { Vapor } \\
\text { Release }\end{array}$ \\
\hline $\begin{array}{c}\text { Combustible Gas } \\
\text { Volume }-\left(\mathrm{m}^{3}\right)\end{array}$ & 7750.3 & 266.57 \\
$\begin{array}{c}\text { Volume Fraction } \\
\text { Fuel - }(\%)\end{array}$ & 6.05 & 6.05 \\
Fuel Volume - $\left(\mathrm{m}^{3}\right)$ & 468.98 & 16.112 \\
$\begin{array}{l}\text { Heat of Combustion } \\
-\left(\mathrm{J} / \mathrm{m}^{3}\right)\end{array}$ & $9.6466 \times 10^{7}$ & $9.6466 \times 10^{7}$ \\
$\varepsilon$ & 1.0 & 1.0 \\
T.N.T. EQ (LB) & 21,444 & 736.9 \\
\hline
\end{tabular}


Unburned Gas Constituents

\begin{tabular}{cr} 
Constituent & Volume \% \\
\hline $\mathrm{C}_{3} \mathrm{H}_{8}$ & 6.10 \\
$\mathrm{~N}_{2}$ & 74.20 \\
$\mathrm{O}_{2}$ & 19.70
\end{tabular}

Burned Gas Constituents

\begin{tabular}{cc} 
Constituent & Volume \% \\
\cline { 1 - 2 } $\mathrm{CO}$ & 11.56 \\
$\mathrm{CO}_{2}$ & 4.18 \\
$\mathrm{H}$ & .05 \\
$\mathrm{H}_{2}$ & 7.28 \\
$\mathrm{H}_{2} \mathrm{O}$ & 13.67 \\
$\mathrm{NO}$ & .002 \\
$\mathrm{~N}_{2}$ & 63.25 \\
$\mathrm{OH}$ & .013
\end{tabular}

Burned Gas Properties

$$
\begin{array}{ll}
P, \operatorname{atm} & -8.63 \\
T, \text { deg K } & -2198 \\
\text { Mol Wt } & -25.408 \\
C_{P}, \frac{\mathrm{Cal}}{\mathrm{gm}^{\circ} \mathrm{K}} & -.3882 \\
\gamma & -1.2590
\end{array}
$$


TABLE VII

SUMURY OF HEAT FLUX CALCULATIONS (CLASSES I and 2)

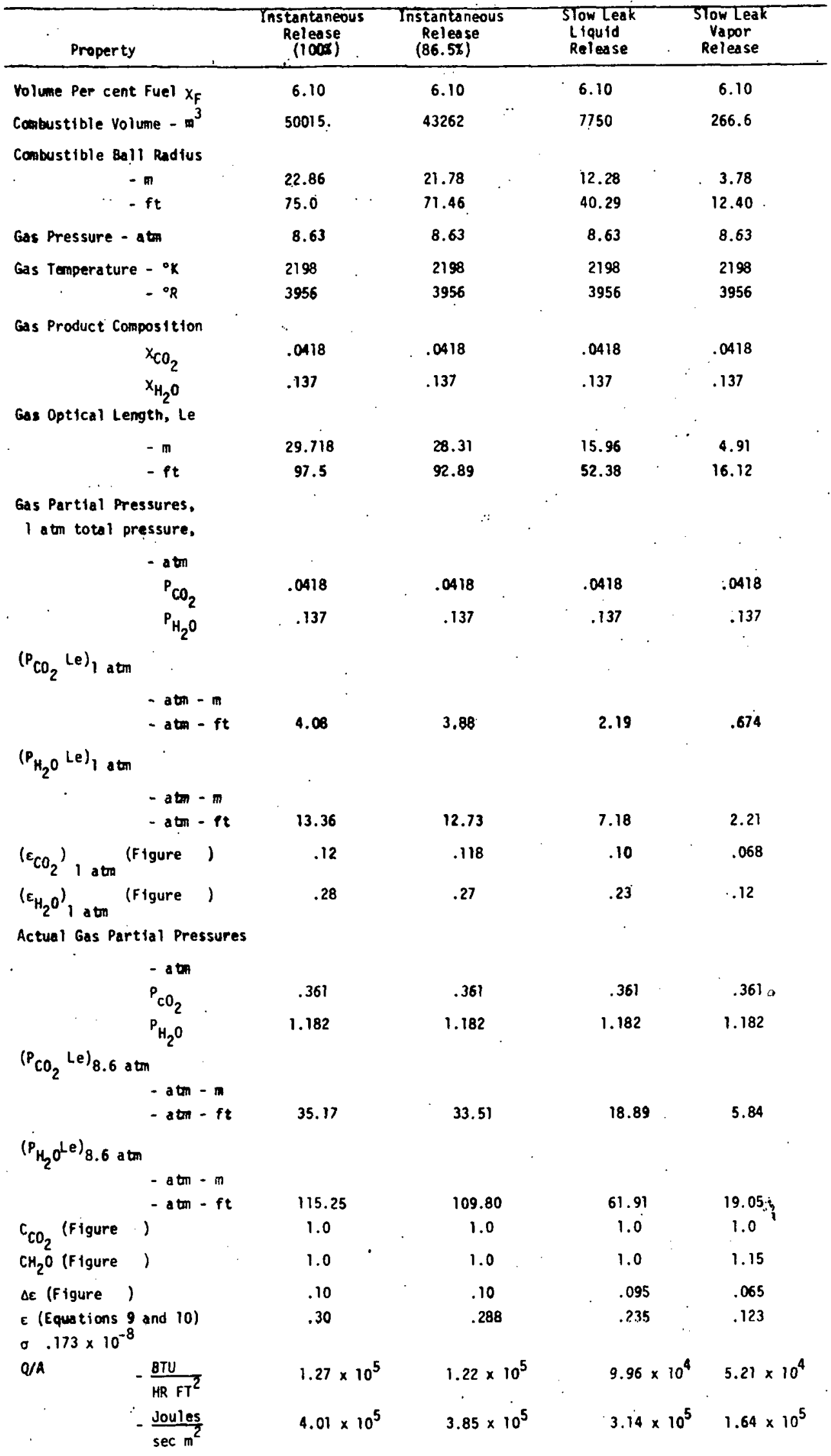




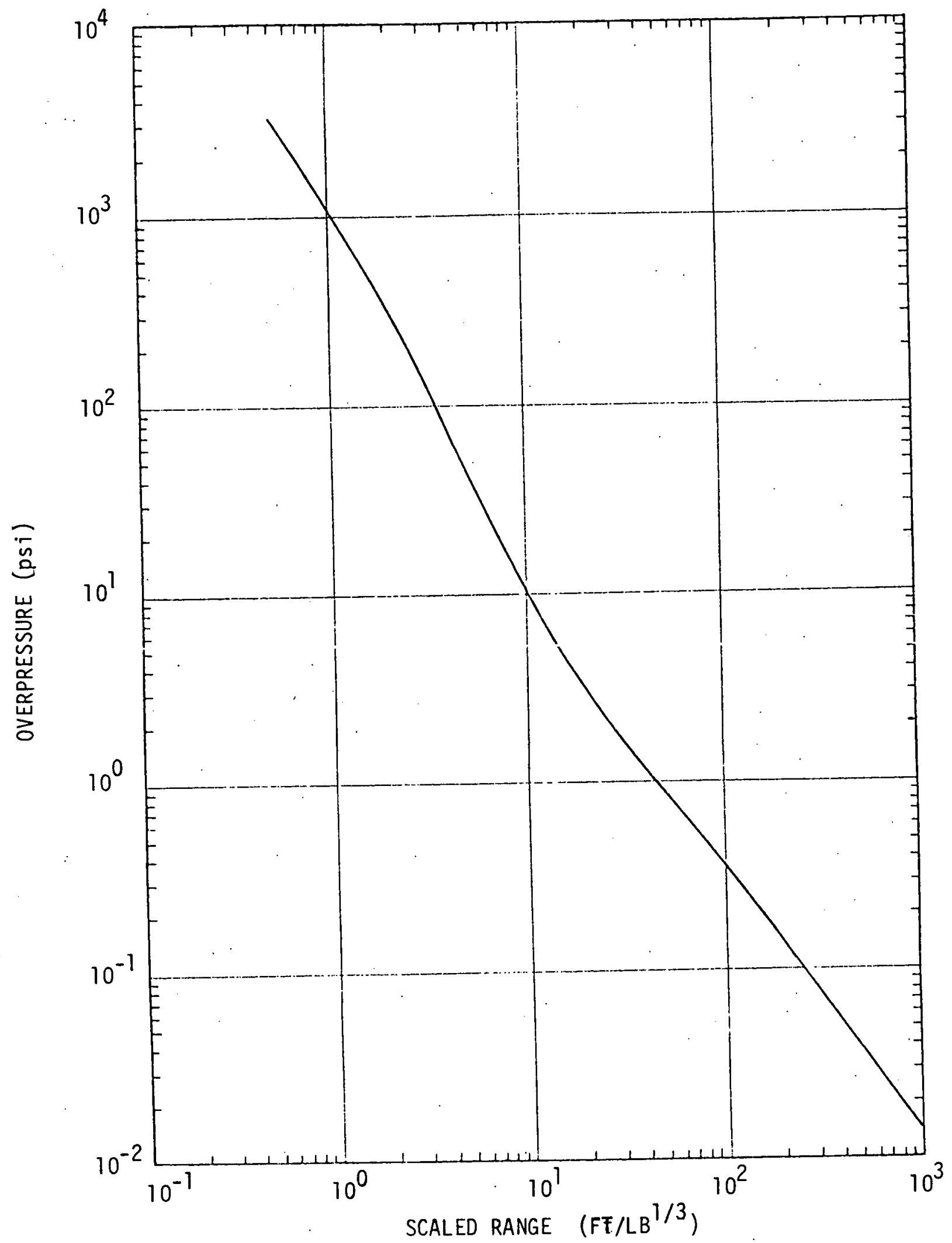

FIGURE 1 - A PLOT OF OVERPRESSURE VS. SCALED RANGE TAKEN FROM DECKER ${ }^{4}$. 


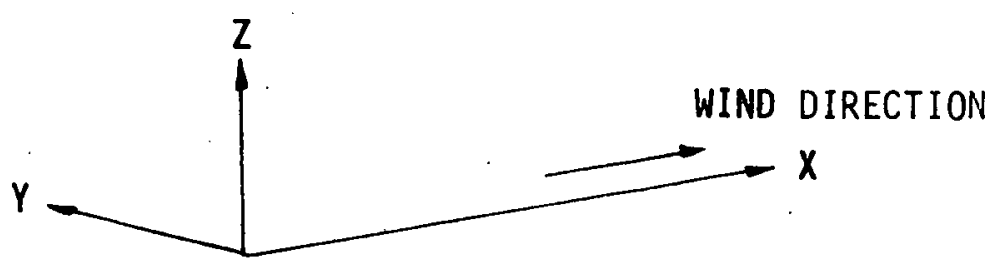

FIGURE 2 - COORDINATE SYSTEM FOR SLOW LEAK CALCULATIONS
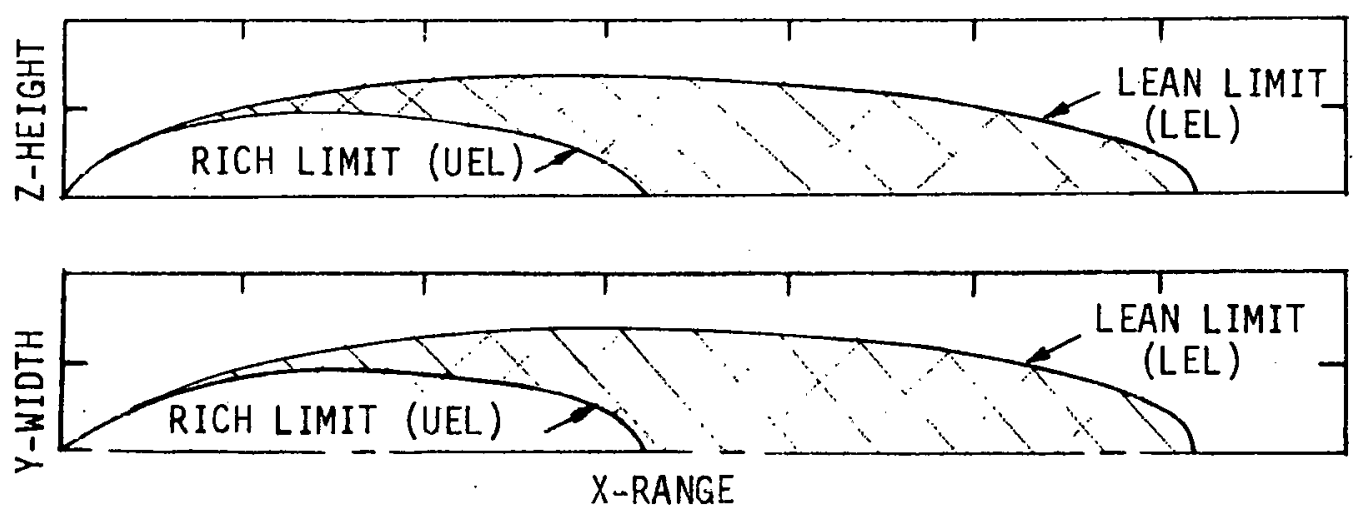

FIGURE 3 - EXAMPLE OF CONCENTRATION ENVELOPES FOR SLOW LEAK CALCULATION 


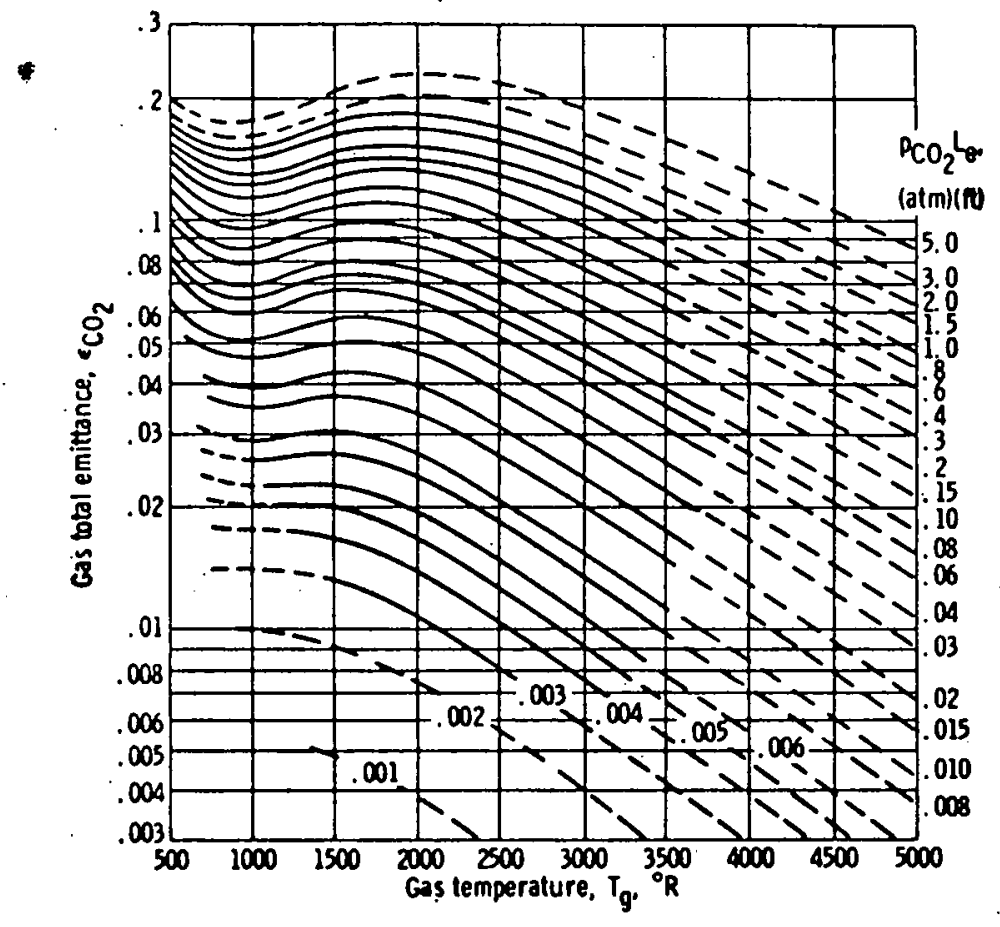

$4 a$ - TOTAL EMITTANCE OF CARBON DIOXIDE IN A MIXTIIRE HAVIIIG A TOTAL PRESSURE OF $1 \mathrm{~atm}$

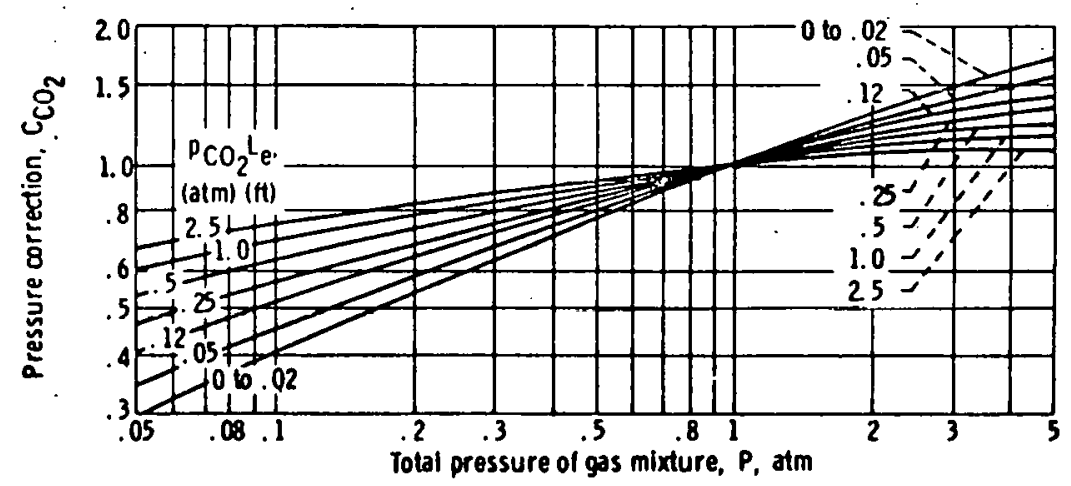

HD -. EREESUEE COREECTIUN FOR $\mathrm{CO}_{2}$ EMITTANCE FOH TOTAL PRESS:BE I'ALUES OTHER THAN 1 a tm

FIGURE 4 - EMITTANCE AND CORRECTION FACTORS FOR CARBON DIOXIDE $\left(\mathrm{CO}_{2}\right)^{7}$ 


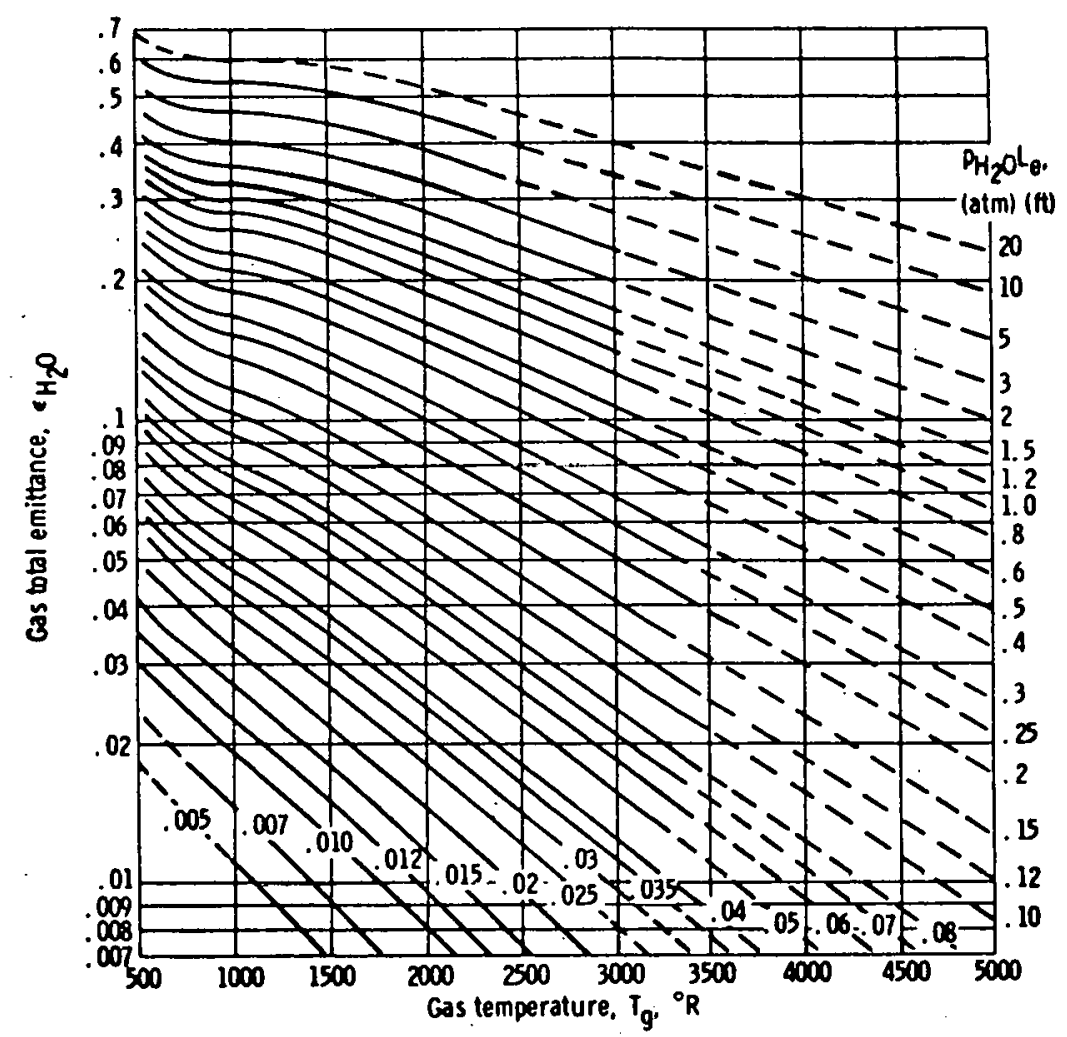

5a - TOTAL EMITTANCE OF WATER VAPOR IN LIMIT OF ZERO
PARTIAL PRESSURE IN MIXTURE OF $i$ a tm TOTAL PRESSURE

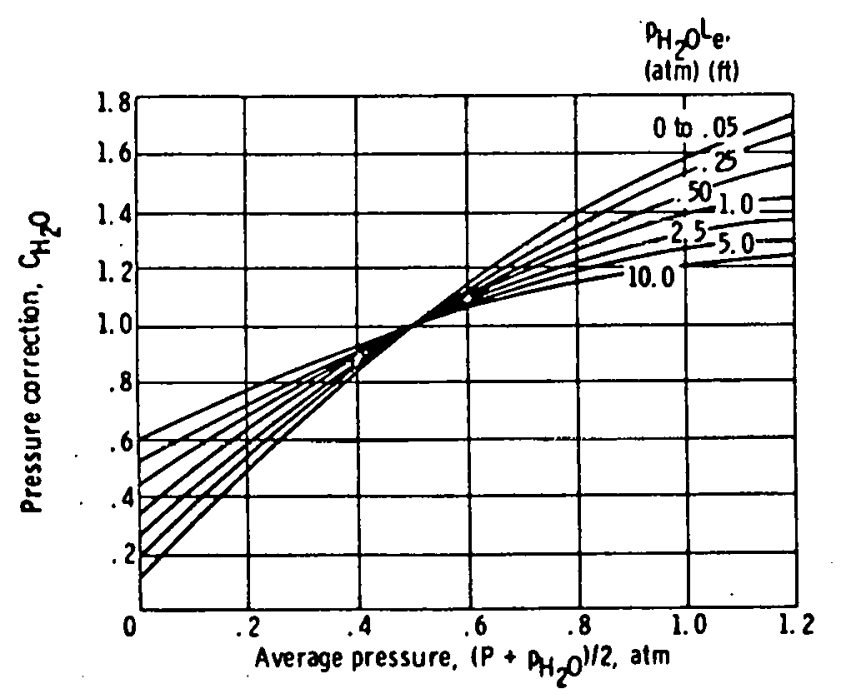

5b - PRESSIJRE CORRECTION FOR WATER VAPOR EMITTANCE FOR PARTIAL AND TOTAL PRESSURE VALUES OTHER THAN $O$ AND $1 \mathrm{~atm}$, RESPECTIVELY

FIGURE 5 - EMITTANCE AND CORRECTION FACTORS FOR WATER VAPOR $\left(\mathrm{H}_{2} \mathrm{O}\right)^{7}$ 


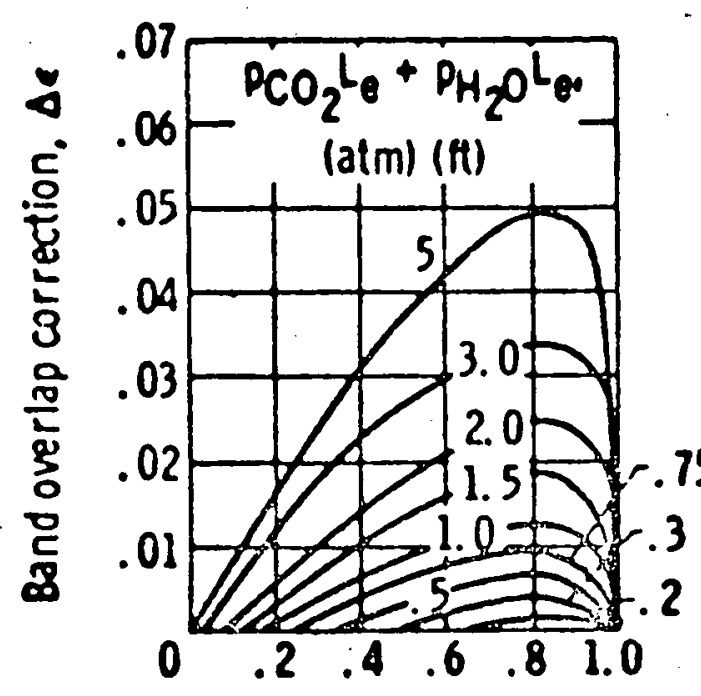

(a)

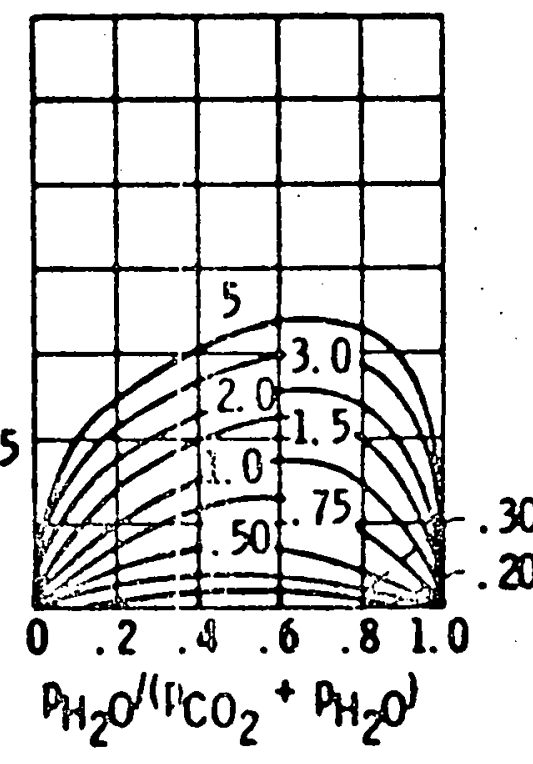

(b)

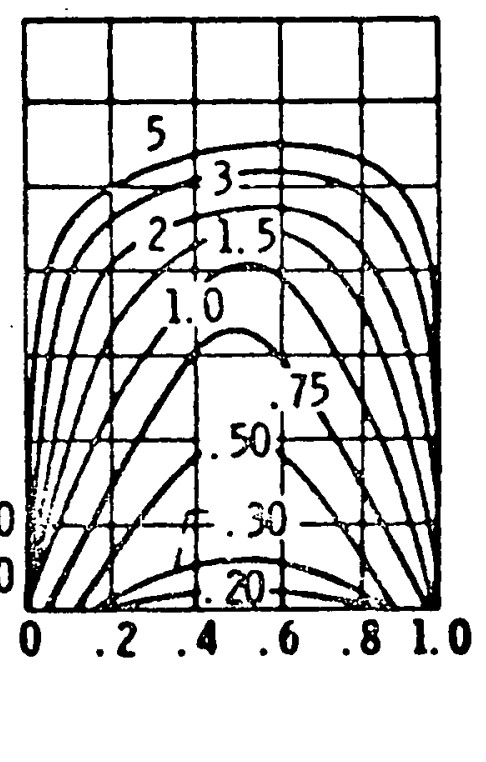

(c)

FIGURE 6 - BAND OVERLAP CORRECTION TO TOTAL EMITTANCE WHEN BOTH $\mathrm{CO}_{2}$ AND WATER VAPOR ARE PRESENT 7 .
a) GAS TEMPERATURE $\mathrm{T}_{\mathrm{g}}=720^{\circ} \mathrm{R}$; b) $\mathrm{T}_{\mathrm{g}}=1460^{\circ} \mathrm{R}$;
c) $T_{g}=2160^{\circ} R$. 


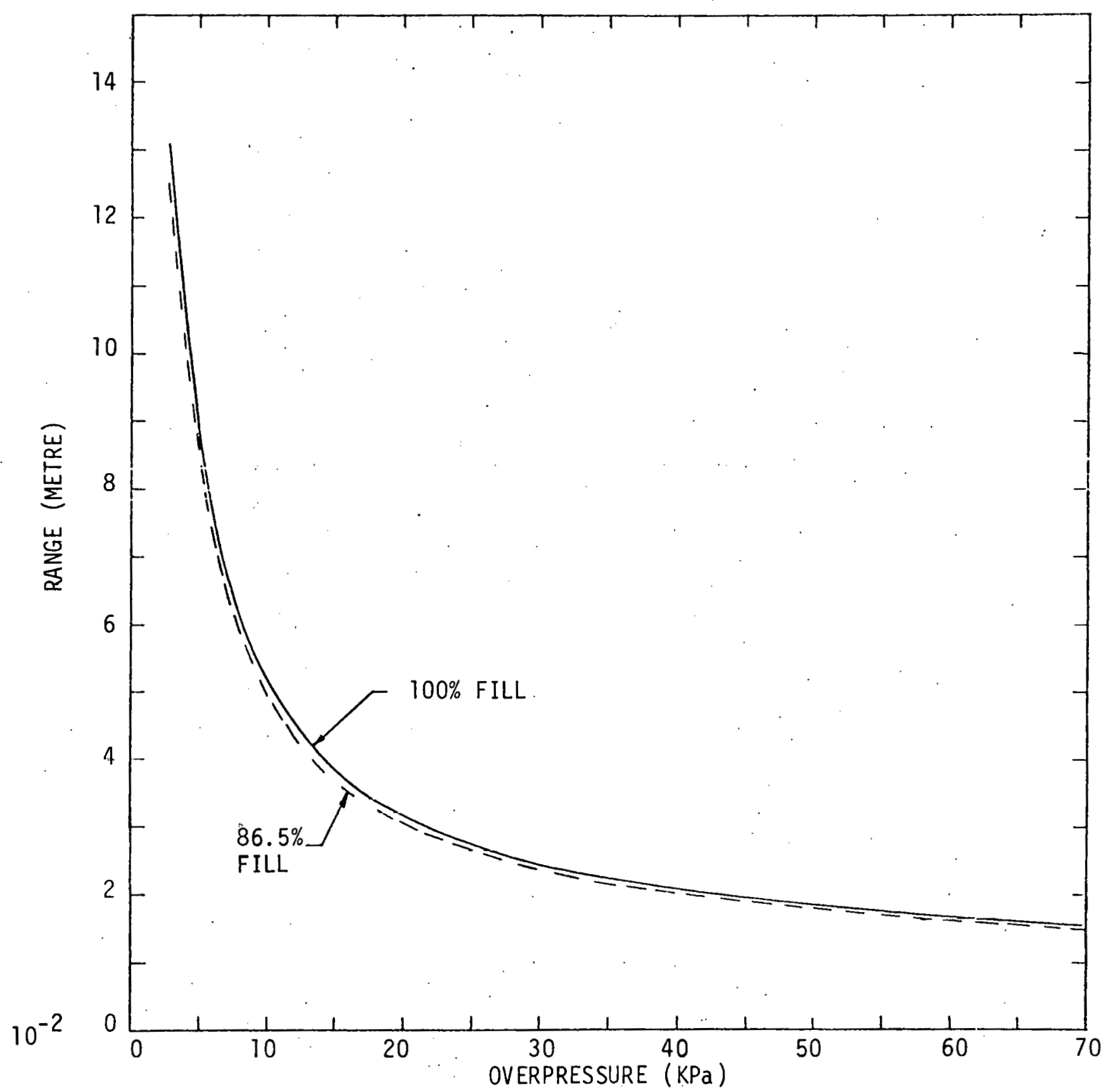

FIGURE 7 - RANGE VS. OVERPRESSURE VALUES FOR CLASS 1 100\% AND 86.5\% FILL SITUATIONS (REFER TO TABLE III) CONVERSIOHI: -1 . PSI $=6.895 \mathrm{RPa}$ 


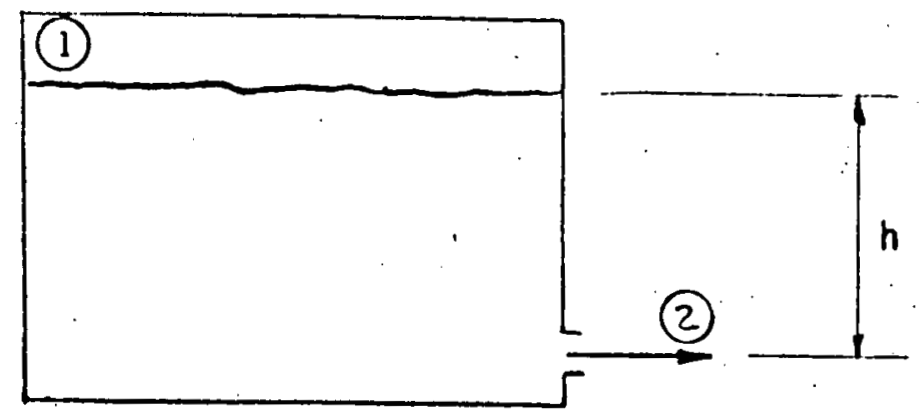

FIGURE 8 - DIAGRAMATIC REPRESENTATION OF CLASS 2
LIQUID DISCHARGE SITUATION

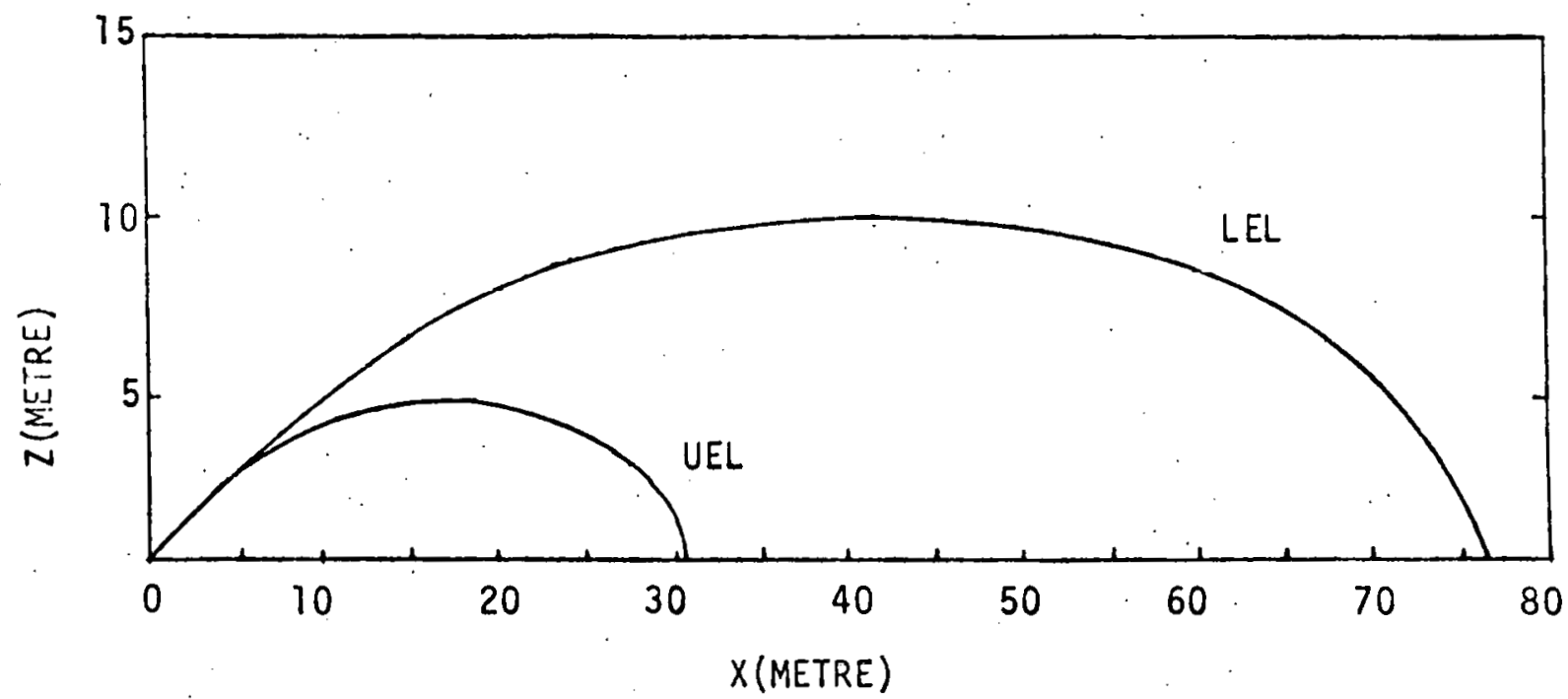

9a - CONCENTRATION CONTOURS IN X-Z PLANE

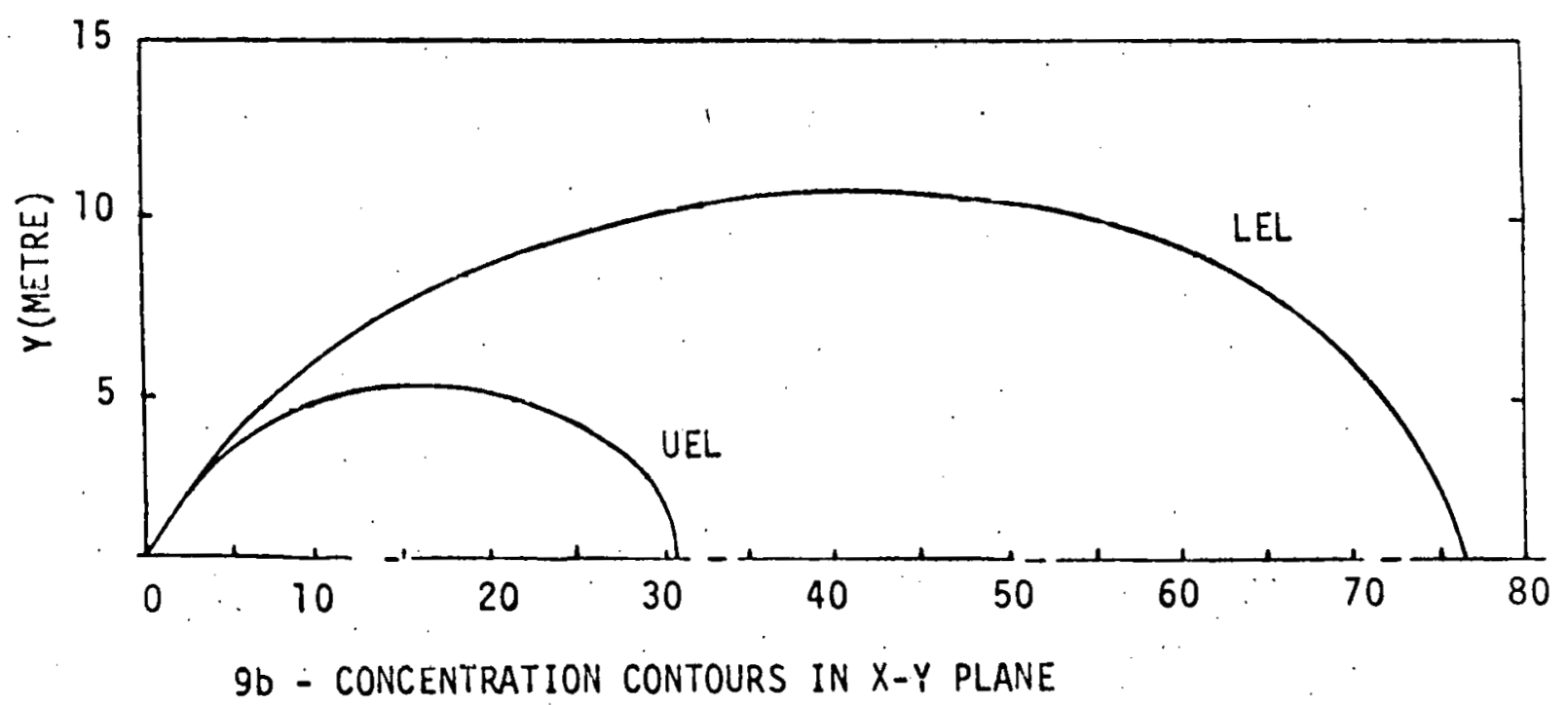

FIGURES 9 - 2.1\% (LEL) AND 10.1\% (UEL) CONCENTRATION CONTOURS FOR CLASS 2 LIQUID DISCHARGE THROUGH A 3 INCH DIAMETER OPENING 


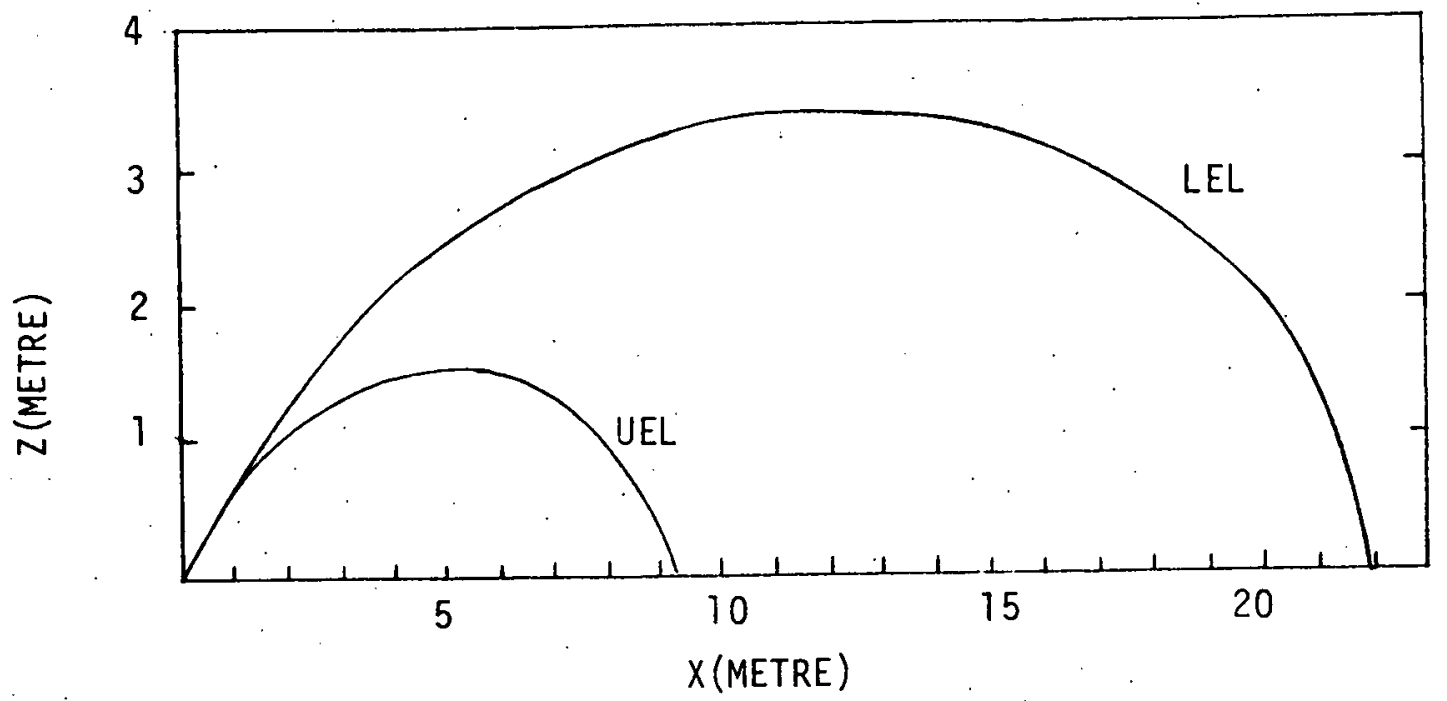

$10 a$ - CONCENTRATION CONTOURS IN X-Z PLANE

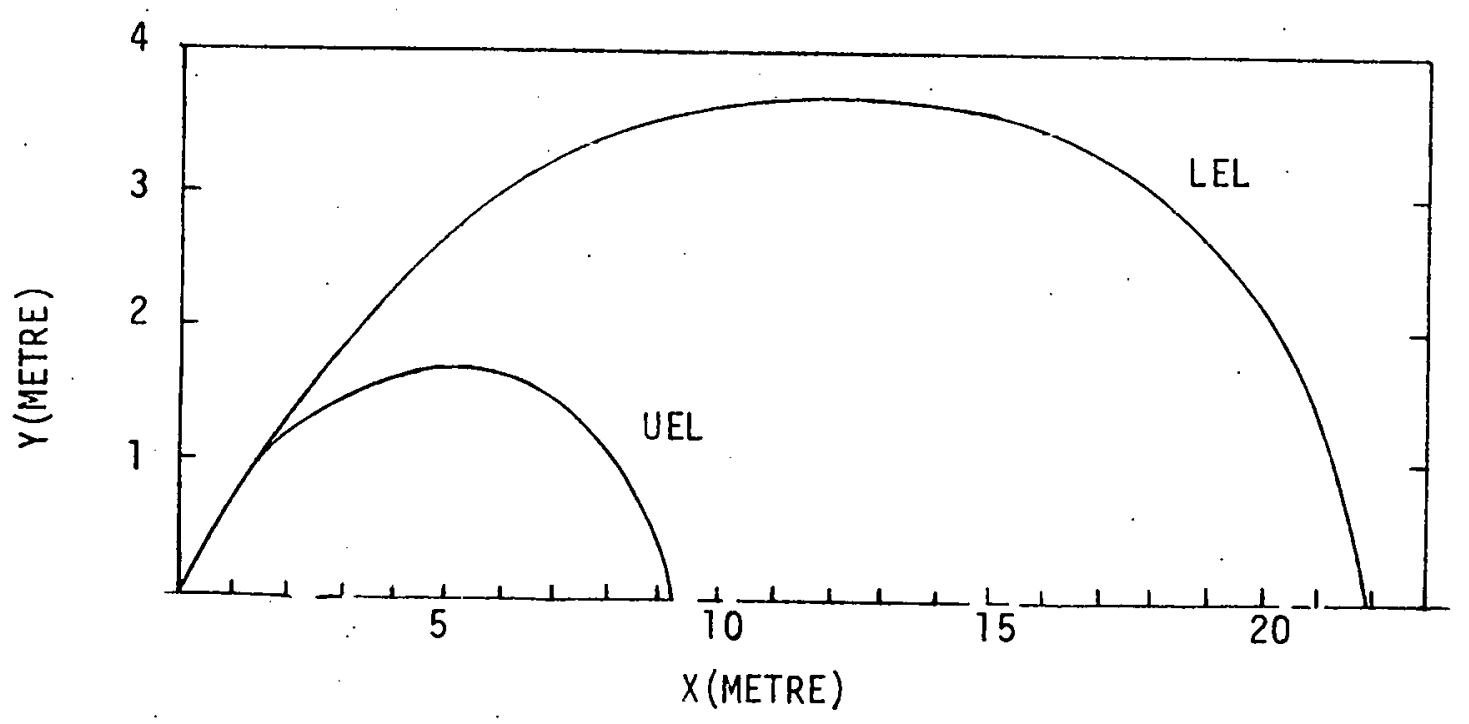

1Ob - CONCENTRATION CONTOURS IN $X-Y$ PLANE

FIGURES $10-2.1 \%$ (LEL) AND $10.1 \%$.(UEL) CONCENTRATION CONTOURS FOR CLASS 2 VAPOR DISCHARGE THROUGH A 3 INCH DIAMETER OPENING 


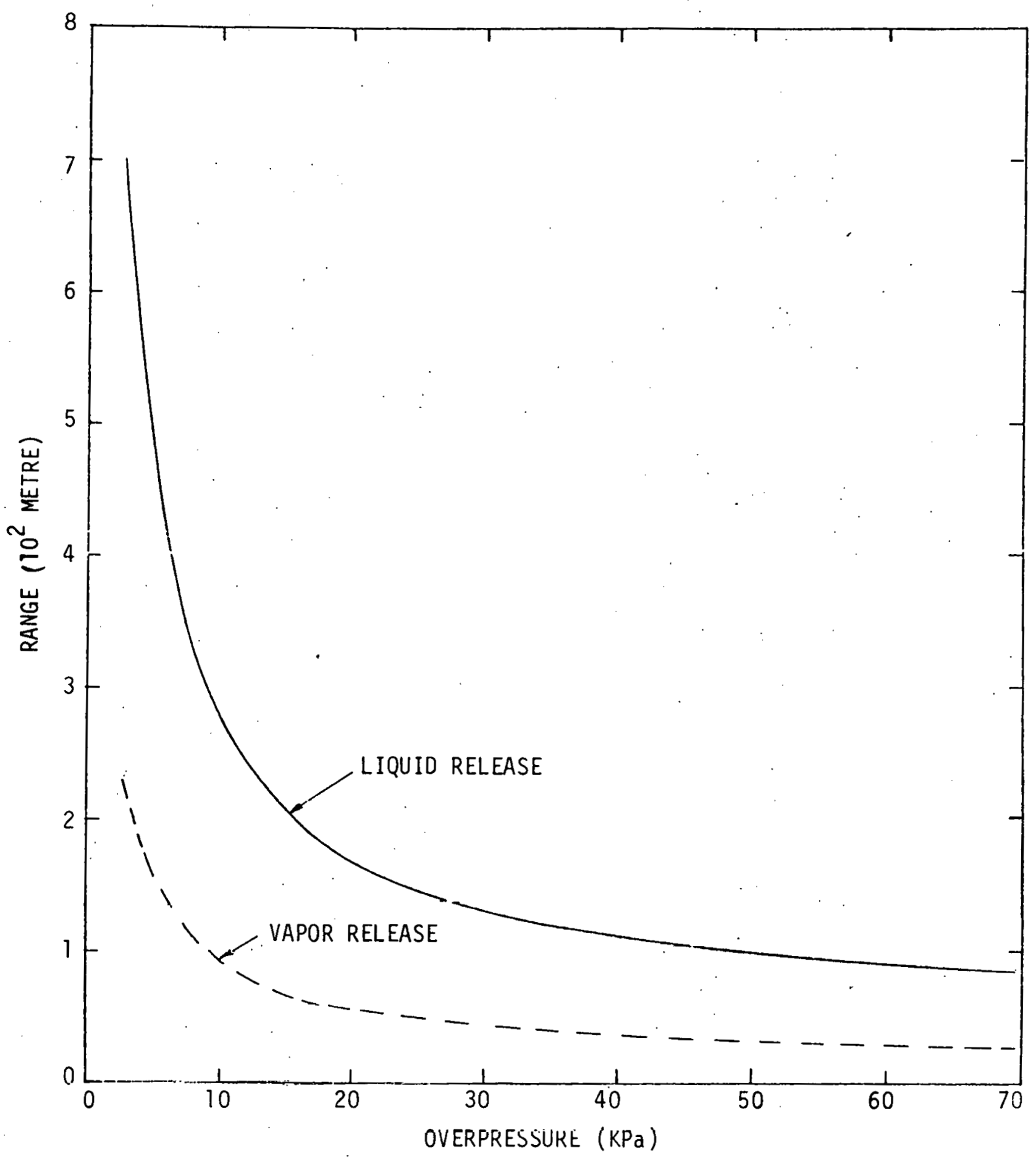

FIGURE 11 - RANGE VS. OVERPRESSURE VALUES FOR CLASS 2 LIQUID AND VAPOR RELEASES THROUGH A 3 INCH DIAMETER OPENING (REFER TO TABLE IV). CONVERSION: I PSI $=6.895 \mathrm{KPa}$ 


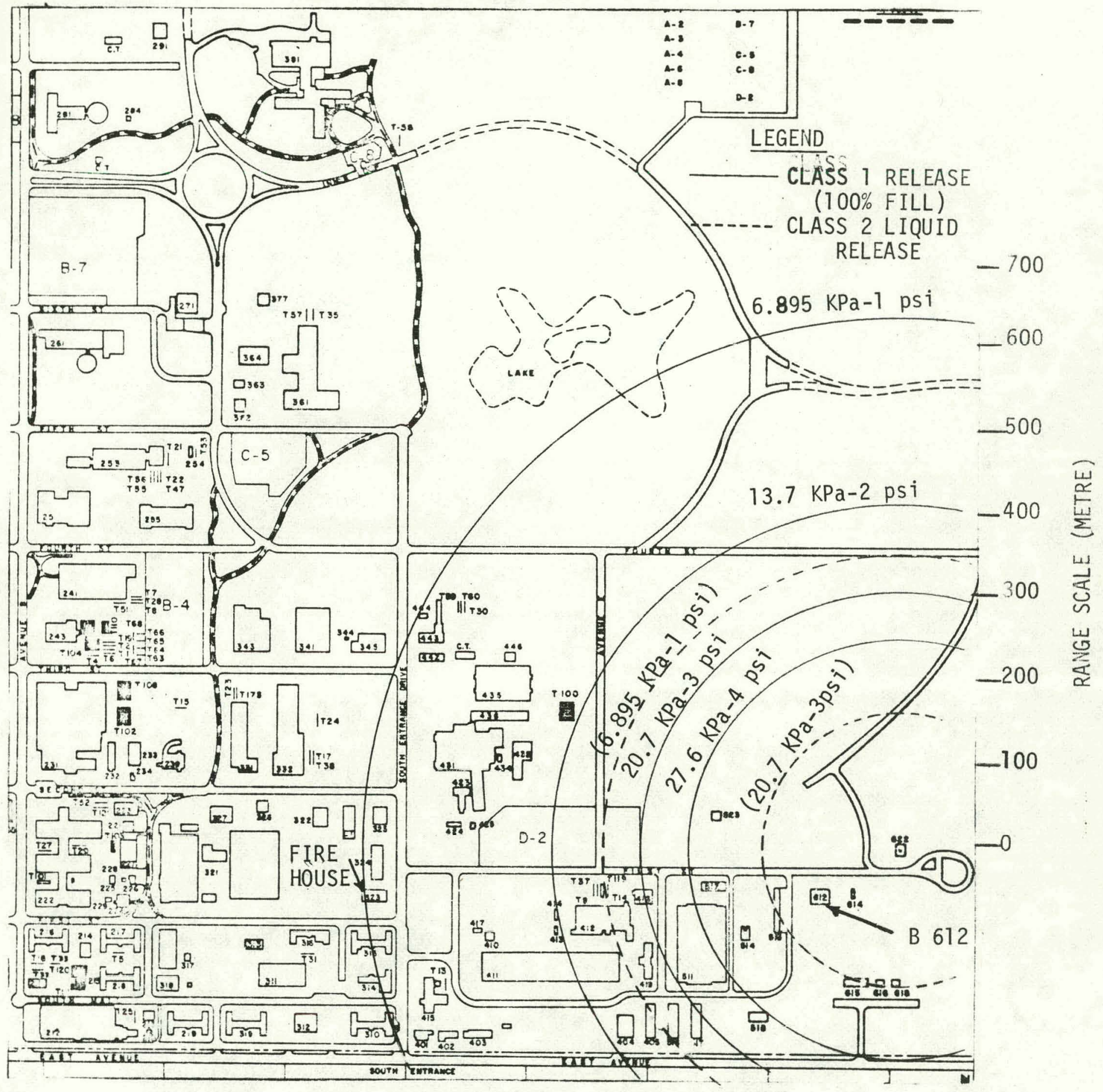

FIGURE 12 - AN OVERLAY OF PREDICTED BLAST SHOCK STRENGTH VS. RANGE ON AN LLL SITE MAP FOR A 100\% VOLUME INSTANTANEOUS RELEASE (SOLID LINES) AND A LIQUID RELEASE SLOW LEAK CASE (DASHED LINES). 
$32-$

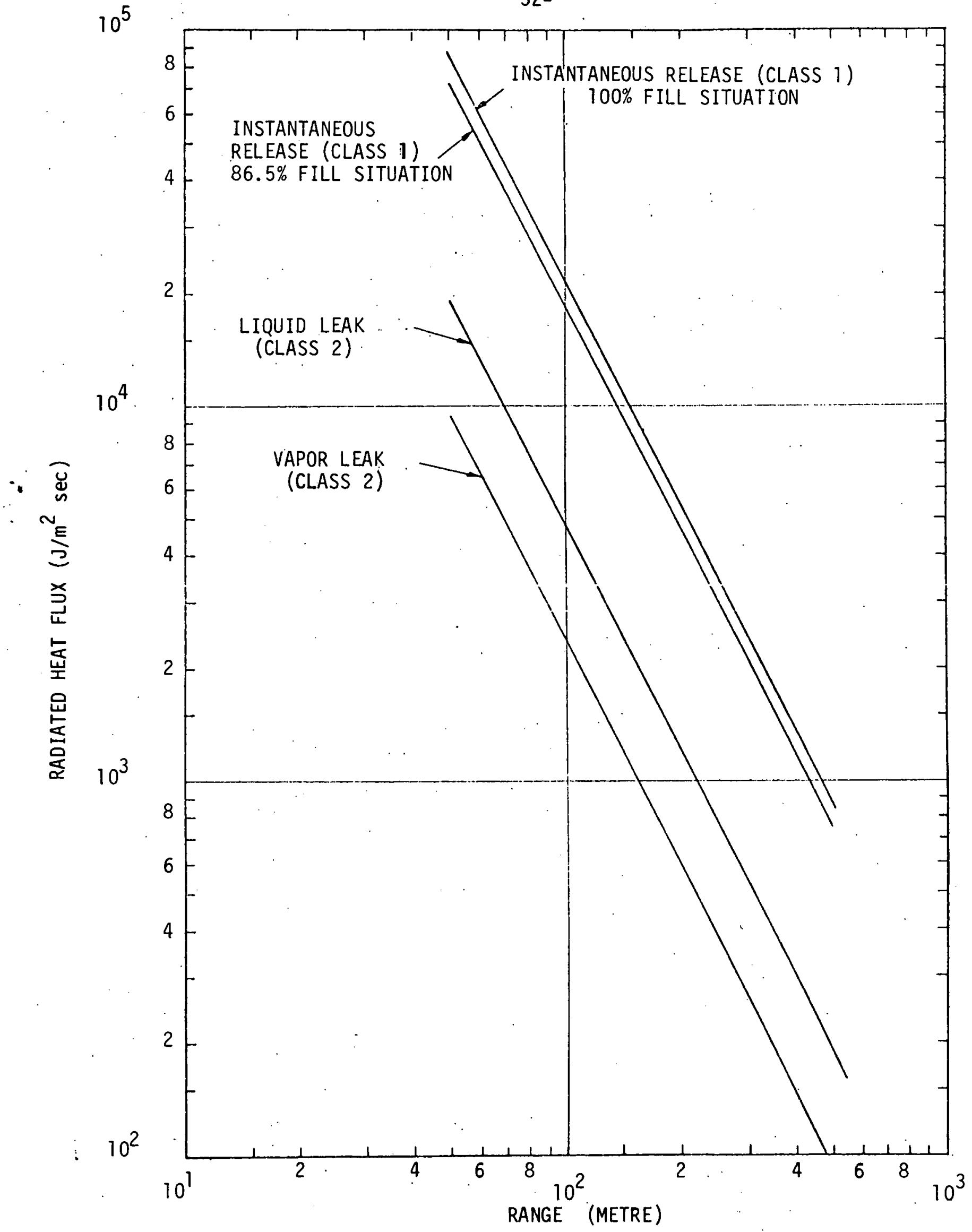

- FIGURE 13 - PLOTS OF RADIATED HEAT FLUX VS. RANGE FOR CLASS 1 (100\% AND 86.5\% FILL SITUATIONS) AND CLASS 2 . (LIQUID RELEASE AND VAPOR RELEASE) CALCULATIONS. 


\section{REFERENCES}

1. Toy, Art, Private Communication (August 1974).

2. Sutton, S. B., "Prel iminary Propane Calculations," EM-74-247, September 1974.

3. Szybalski, S., Private Communication (Nov. 1974).

4. Decker, D. A., "An Analytical Method of Estimating Overpressure from Theoretical Atmospheric Explosions," Presented at 1974 Annual Meeting of the National Fire Protection Association, May 23, 1974.

5. Brasie, W. D. and Simpson, D. W., Guidel ines for Estimating Damage Explosions, CEP Technical Manual, Loss Prevention Volume 2, American Institute of.Chemical Engineers, New York, 1968.

6. Bowman, B. R. and Sutton S. B., "CCC, Complex Chemical Calculations," Lawrence Livermore Laboratory, ENN-74-70, May 1974.

7. Siegel, R., Howell, J. R., Thermal Radiation Heat Transfer, McGraw-Hi11, New York, 1972.

8. Murray, R. C., Private Communication (Jan. 1975).

9. Simms, D. L., "On The Pilot Ignition of Wood by Radiation," Combustion and Flame, September 1963.

10. Martin, S., Stanford Research Insitute, Private Communication (Nov. 1974).

11. Fu, T. T., "Heat Radiation from Fires of Aviation Fuel," Fire Technology, Feb. 1974.

12. Parker, R. 0., "Calculated Thermal Radiation Hazards in Large Fires," Fire Technology, May 1974. 


\section{External:}

Dr. Frank A. Morrison, Jr. Mechanical and Industrial

Engineering Department University of Illinois at Urbana-Champaign Urbana, Illinois 61801

TIC, Oak Ridge, TN

R. Purington, $L-519$

W. Silver, $L-518$

S. Sutton, $L-90$

S. Szybalski, L-345

F. Tokarz, L-90

A. Toy, $L-518$

TID File, L-9

\section{NOTICE}

"This report was prepared as an account of work sponsored by the United States Covernment. Neither the United States nor the United States Energy Research \& Development Administration. nor any of their employees, nor any of their contractors, subcontractors, or their empluyees, makes any warranty, express or implied, or assumes any legal liability or responsibility for the accuracy, completeness or usefulness of any information. apparatus, product or process disclosed, or represents that its use would not infringe privately-owned rights.";

Printed in the United States of America Available from

National Technical Information Service

U.S. Department of Commerce 5285 Port Royal Road

Springfield, Virginia 22151

Price: Printed Copy $\$ \_$* * Microfiche $\$ 2.25$

$*$ Pages
$1-50$
$51-150$
$151-325$
$326-500$
$501-1000$

NTIS

Selling Price

$\$ 4.00$

$\$ 5.45$

$\$ 7.60$

$\$ 10.60$

$\$ 13.60$ 